\section{International Scientific Journal Theoretical \& Applied Science}

Nikolay Vasilevich Penshin candidat of economic sciences, Head of the Department "Organization of transportation and road safety" Tambov state technical University avtobd@mail.ru

Victor Yurievich Ivlev Undergraduate, Mechanical engineer Aor Nekrasovskoe RTP, city of Rasskazovo victor.pshenihniy_7@mail.ru

SECTION 27. Transport.

\title{
IMPROVING ROAD SAFETY BY IMPROVING TSODD FOR MAC
}

Abstract: The article deals with the most modern and effective technical means of traffic (TSODD) and their impact on the level of accidents on the road network (MAC) of the city.

Key words: motor media-tion, road safety, Vod-Tel, traffic, technical means of traffic, street and road network, the level of accidents on the road network.

Language: Russian

Citation: Penshin NV, Ivlev VY (2015) IMPROVING ROAD SAFETY BY IMPROVING TSODD FOR MAC. ISJ Theoretical \& Applied Science 12 (32): 62-66.

Soi: http://s-o-i.org/1.1/TAS-12-32-12 Doi: crossef http://dx.doi.org/10.15863/TAS.2015.12.32.12

\section{ПОВЫШЕНИЕ БЕЗОПАСНОСТИ ДОРОЖНОГО ДВИЖЕНИЯ ПУТЕМ СОВЕРШЕНСТВОВАНИЯ ТСОДД НА УДС}

Аннотация: В статье рассматриваются наиболее современные и эффективные технические средства организачии дорожного движения (ТСОДД) и их влияние на уровень аварийности на уличнодорожной сети (УДС) города.

Ключевые слова: автотранспортное средство, безопасность дорожного движения, водитель, дорожное движение, технические средства организачии дорожного движения, улично-дорожная сеть, уровень аварийности на улично-дорожной сети.

\section{УДК 502.7}

В современных условиях одной из наиболее главных проблем транспортной отрасли в городах России выступает стихийный рост автомобилизации населения.

Безопасностью дорожного движения является комплекс мероприятий, которые направлены на обеспечение безопасности абсолютно всех участников дорожного движения.

Безопасностью же дорожного движения, согласно российского законодательства, является состояние указанного процесса, которое отражает степень защищенности от дорожно-транспортных происшествий, а также их последствий его участников [9, с.10].

Дорожно-транспортное происшествие (ДТП) представляет собой событие, которое возникает в результате процесса движения транспортного средства по дороге, из-за которого причинен ущерб [2, с.112].

Дорожные происшествия выступают во всем мире главной угрозой здоровью и, кроме того, жизни людей. Ущерб в следствие дорожно- транспортных происшествий оценивается гораздо выше нежели ущерб от всех других транспортных происшествий (с участием поездов, кораблей, самолетов и т.п.) вместе взятых.

Проблема усугубляется еще и тем, что пострадавшие в авариях, чаще всего, здоровые (до аварии) и молодые люди.

Ежегодно в мире в дорожных авариях погибает около 1,2 млн. человек и, кроме того, примерно 50 млн. получает травмы. Более чем 35 тыс. погибает на российских дорогах [11].

На автомобильном транспорте аварийность наносит собой достаточно огромный материальный и моральный ущерб в целом обществу, а также отдельным гражданам. В результате дорожно-транспортного травматизма исключаются трудоспособные граждане из сферы производства. Кроме того, гибнут или же становятся инвалидами дети.

По статистике, ежегодно в России в результате ДТП получают ранения или же 
погибают более 275 тысячи человек. За последние 9 лет на дорогах травмированы 209223 ребенка и, кроме того, погибло 9852 ребенка, имеющие возраст до 16 лет. От ДТП, а также их последствий за 2007-2014 годы демографический ущерб составил 571407 человек (табл.1) [10].

\section{Статистика ДТП в России за 2013-2014 гг.}

Таблица 1

\begin{tabular}{|c|c|c|c|c|c|}
\hline \multicolumn{2}{|c|}{ ДТП } & \multicolumn{2}{c|}{ Погибло } & \multicolumn{2}{c|}{ Ранено } \\
\hline 2013 г. & 2014 г. & 2013 г. & 2014 г. & 2013 г. & 2014 г. \\
\hline 199868 & 203597 & 27953 & 27991 & 251848 & 258618 \\
\hline
\end{tabular}

Что касается Тамбовской области, то статистика ДТП в 2014 году представлена в таблице 2 [10].

Таблица 2

Статистика ДТП по Тамбовской области за 2014 год.

\begin{tabular}{|c|c|c|c|c|c|c|}
\hline \multicolumn{2}{|c|}{ ДТП } & \multicolumn{2}{|c|}{ Погибло } & \multicolumn{2}{|c|}{ Ранено } & \multirow{2}{*}{$\begin{array}{c}\text { Тяжесть } \\
\text { последствия } \\
\text { ДТП }\end{array}$} \\
\hline человек & $\begin{array}{c} \pm \% \text { к } \\
\text { АППГ }{ }^{1}\end{array}$ & человек & $\begin{array}{l} \pm \% \text { к } \\
\text { АППГ }\end{array}$ & человек & $\begin{array}{l} \pm \% \text { к } \\
\text { АППГ }\end{array}$ & \\
\hline 1794 & $-1,9$ & 211 & $-2,8$ & 2465 & $-4,4$ & 7,9 \\
\hline
\end{tabular}

Безопасность при дорожном движении обеспечивается безотказностью всех звеньев комплекса «среда - дорога - автомобиль водитель». Надежность работы данного комплекса должна обеспечиваться техническим совершенством дороги и технической надежностью автомобиля, а также надежностью действий водителя в разных дорожнотранспортных ситуациях. Центральным звеном в указанной системе выступает водитель, под надежностью которого понимают его способность своевременно и правильно выбирать наиболее оптимальный режим движения и оценивать ситуацию [9, с.12].

Статистика утверждает, что доля дорожнотранспортных происшествий, совершенных по вине водителя, колеблется в районе $85 \%$. Основной причиной дорожно-транспортных происшествий является нарушения водителем Правил дорожного движения. Отсюда, в качестве основного способа борьбы с высокой аварийностью на дороге, используют усиление карательных мер за нарушение ПДД. Однако, этот способ борьбы, учитывая отсутствие неотвратимости наказания, показывает недостаточную эффективность [11].

Для безопасного движения по дорогам следует выполнять ряд требований:

- строгое соблюдение пешеходами и водителями правил дор ожного движения (ПДД);

- хорошее техническое состо яние транспортных средств;

- обеспечение планом и продольным профилем дороги беспрепятственного движения $\Pi^{1}$ отока автомобилей расчетной интенсивности с заданной скоростью;

- поддержание службой ремонта и содержания транспортно-эксплутационных качеств дороги;

- повышение профессионального мастерства водителей.

Одним из инновационных способов снижения аварийности дорожного движения выступает применение шумовой полосы. Указанный метод заключен в устройстве выемок шириной 10-15 см, длиной 20-35 см, глубиной 10 см вдоль дороги (рис. 1) [9, с.86].

\footnotetext{
1 - АППГ - аналогичный период прошлого года
} 


\begin{tabular}{l|lrl|l|ll} 
& ISRA (India) & $=\mathbf{1 . 3 4 4}$ & SIS (USA) & $=\mathbf{0 . 9 1 2}$ & ICV (Poland) & $=\mathbf{6 . 6 3 0}$ \\
Impact Factor: & ISI (Dubai, UAE) $=\mathbf{0 . 8 2 9}$ & PUHU (Russia) $=\mathbf{0 . 1 7 9}$ & PIF (India) & $=\mathbf{1 . 9 4 0}$ \\
& GIF (Australia) & $\mathbf{0 . 5 6 4}$ & ESJI (KZ) & $=\mathbf{1 . 0 4 2}$ & & \\
& JIF & $=\mathbf{1 . 5 0 0}$ & SJIF (Morocco) $=\mathbf{2 . 0 3 1}$ & &
\end{tabular}

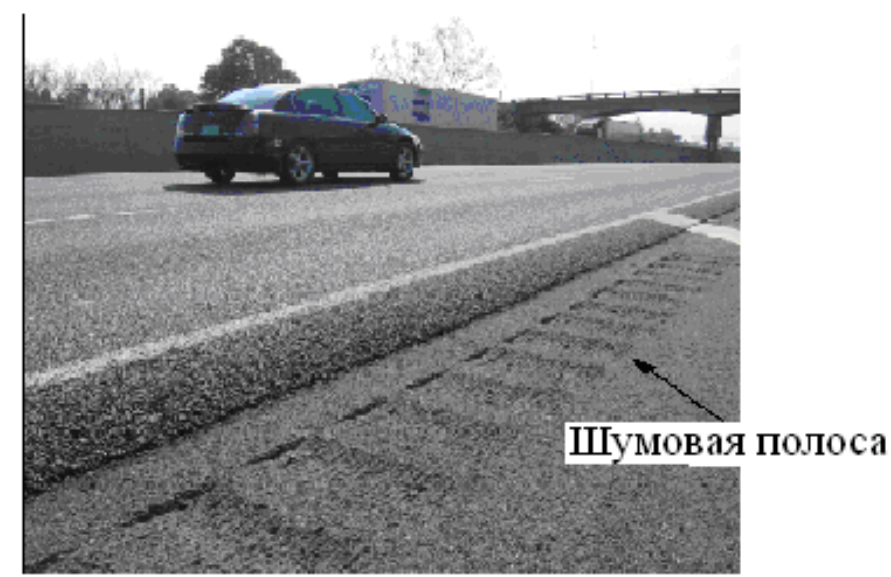

Рисунок 1 - Шумовая полоса на автомагистрали.

Основной задачей шумовой полосы является привлечение внимания отвлекшихся водителей.
Одним из эффективных методов снижения аварийности на дорогах является метод автодории, который применяется за рубежом (рис.2).

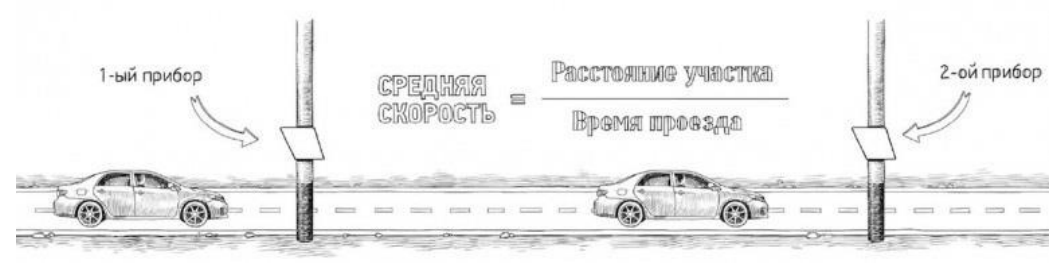

Рисунок 2 - Автодория.

Данный метод заключается в том, что на участке дороги с измеренным заранее расстоянием с интервалом в несколько десятков километров ставятся детекторы, которые невозможно объехать. Камеры фиксируют номер и время проезда автомобиля, а центральный компьютер по данным с детекторов на всем участке дороги высчитывает среднюю скорость его движения.

Начиная с 2011 года, придорожные камеры применяются на $90 \%$ российских дорог.

На загруженных магистральных дорогах с целью повышения безопасности дорожного движения следует выполнить следующие мероприятия с использованием технических средств организации дорожного движения, которые активно применяются во многих странах Европы, что позволило значительно повысить безопасность дорожного движения:

- установка железобетонных ограждений парапетного типа вдоль центральной разделительной полосы.

УДС большинства российских городов уже давно исчерпала резервы пропускной способности, большую часть времени суток на дорогах наблюдаются заторы, ухудшающие условия движения, экологическую обстановку, снижается комфортность проживания в данных условиях.

В указанных условиях особую актуальность приобретает проблема совершенствования УДС российских городов. Т. к. уровень оснащенности техническими средствами организации дорожного движения все еще остается недостаточно высоким, необходимо наращивать темпы внедрения новой техники и методов регулирования. Разумным является заимствование и адаптация зарубежных разработок в данной области, т. к. в силу объективных причин длительное время большая часть российской научной среды пребывает в состоянии стагнации

Геометрические параметры кольцевых пересечений, обеспечивающие плавное слияние и разделение транспортных потоков, их техническое обустройство с помощью инновационных методик оптимизации условий организации дорожного движения, оснащение дополнительными дорожными знаками и уличным освещением, а также барьерными 
ограждениями в соответствии с необходимыми требованиями позволят решить многие проблемы в области обеспечения безопасности дорожного движения.

При достаточно большом количестве достоинств кольцевых пересечений есть и недостатки. В число которых входит необходимость большой площади земли, что увеличивает стоимость строительства. Тем не менее, затраты на строительство кольцевых развязок значительно ниже, чем при возведении многоуровневых развязок. Обычно кольцевые развязки выделяются бортовым камнем, либо пластиковым ограждением, которые предотвращают движение по центральному островку, что важно в условиях наличия большого числа недостаточно дисциплинированных водителей вследствие невысокого уровня водительской подготовки. Для повышения пропускной способности на достаточно загруженных направлениях используются выделенные полосы движения для правоповоротного потока, которые дают возможность проезда, минуя кольцевую часть пересечения и не создавая помех попутным потокам с иных направлений.

В целом же, практическая значимость предлагаемых мероприятий играет важную роль в области обеспечения безопасности дорожного движения, условий прохождения транспортного потока, и режима работы автомобильной дороги как инженерного сооружения

Интересен опыт Швеции, которая является лидером в области безопасности на дорогах.

Больше всего снизить аварийность помогает грамотное планирование. Шведские дороги модернизируются и прокладываются, в первую очередь, опираясь на безопасность, а затем на удобство и скорость. В населенные пункты при въезде устанавливается скоростное ограничение 50 км/ч, а иногда и 30 км/ч.

На автострадах встречные полосы разделены, кроме того, выделяется отдельная полоса для велосипедистов. В наибольшей степени уменьшению числа ДТП поспособствовало строительство дорог по новому типу «два плюс один» - это дорога с тремя полосами, из которых две для одного направления и одна для встречного.

В перспективе шведы планируют массово оснастить авто системами блокировки и оповещения машины при обнаружении выпившего водителя, оповещения не пристегнутом ремне безопасности или о несоблюдении скоростного режима, а также предотвращения фронтальных столкновений. Также планируется функции управления доверить автопилотам.

В настоящее время в Российской Федерации действует Федеральная целевая программа «Повышение безопасности дорожного движения в 2013 - 2020 годах», которая направлена на снижение смертности в ближайшие годы на дорогах в несколько раз.

Решение же в России проблемы безопасности на дорогах зависит от серьезности ее осознания каждым участником дорожного движения, всем обществом, государственным деятелем, чиновником, сотрудником ГИБДД.

Поэтому, государственным деятелям нашей страны необходимо разрабатывать и применять технические средства организации дорожного движения в целях сокращения количества дорожно-транспортных происшествий и снижения тяжести их последствий, а также использовать опыт других стран.

\section{References:}

1. (2012) Rasporyazh1enie 271 RF Government of October 2012 № 1995-r Konts1eptsi1i federal target programmy "Safer dorozhn1ogo movement in 2013 - 20201 years" [electronic resource] Available: http://www.garant.ru (Accessed: 20.12.2015).

2. Hambardzumyan V (2010) Bezopasnost traffic. Scientific and practical metody improve road safety. - Moscow: 2010. - 3501 p.

3. (2014) AV boots Problems rose-sheniya bezopasn1osti // traffic organization and safety of motion-dorozhnogo of 2014. - №4.- pp. 111113.
4. Vasilenko VA (2013) Psycho-logicheskie particular driver as faktor road safety dvizheniya // Young scientist. - 2013. - №12. pp. 309-312.

5. Vrubel Yu (2012) Voditelyu of pre-road traffic: a tutorial. - Mn .: BNTU, 2012. - 1129 p.

6. Vrubel YA (2011) Organizatsiya-up road traffic: the textbook. - Mn.: Fund Council, without traffic, 2011. - $634 \mathrm{p}$.

7. Klinkovshteyn GI (2011) Organizatsiya traffic: study Pozo Bie. - Moscow: Transport, 2011. $246 \mathrm{p}$. 


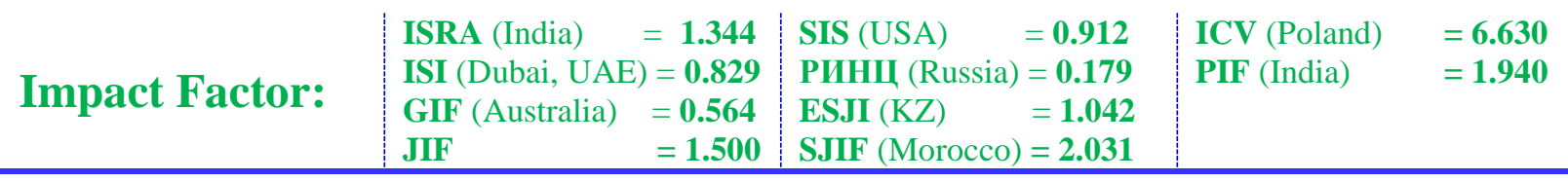

8. Konoplyanko VI (2011) Organizatsiya dvizheniya and road safety: the textbook. Moscow: Transport, 2011. - 1183 p.

9. Vladimir Mayorov (2014) Soderzhanie in adoption "Road safety dvizheniya" // Theoretical bases. - 2014. - №7. - pp. 110-12.

10. (2015) Legal protection motorist [electronic resource]. http://www.vashamashina.ru (Accessed: 20.12.2015).

11.(2015) Federal State statis1tiki [electronic resource]. - Available: $\underline{\text { http://Gks.ru }}$ (Accessed: 20.12.2015).

12. YUSHKOV VS (2015) noise bandwidth to reduce accidents on the road doro-gah // Young scientist. - 2015. - №3. - pp. 86-87. 